\title{
Clare Gerada: Dissecting resilience
}

\author{
Clare Gerada GP partner
}

Hurley Group, London, UK

The traditional structures that have helped doctors prepare themselves psychologically for a career in medicine are changing rapidly or disappearing altogether.

I started medical school over 40 years ago. In my first week I joined my first medical group-for dissection. The groups were allocated alphabetically, and mine was made up of students with surnames beginning with E-K. For the next two years we met over the cadaver for three hours a day, four days a week.

Decades later we still meet, though usually without a dead body in sight. We've become lifelong friends and borne witness to each other's personal and professional milestones along the way. We learnt anatomy together, but our work group provided so much more than just learning. ${ }^{1}$ Our discussions over the dissecting table helped us through the important first steps in becoming a doctor, preparing us for that vital transition from layperson to health professional. ${ }^{2}$

Our discussions helped us through the important first steps in becoming a doctor

Once qualified, we had plenty of new opportunities to form strong attachments with other medical professionals. These ranged from our training groups to our close knit medical firms, doctors' messes, dining rooms, and general practice partnerships.

These groups served a purpose. As well as helping us learn the skills required for the job, they provided support during difficult times. They also helped us to develop coping mechanisms to sustain us in a life spent so close to suffering.

Put simply, in those informal spaces we developed the psychological resilience required for a career in medicine, particularly the unconscious defences we needed in order to distance ourselves from the patients we cared for.
Many factors are contributing to the rise of mental illness in doctors. And many of these are externally facing-for example, the lack of resources to do the job expected of us, the industrialisation of our craft, and the constant cycle of reorganisation.

Closer to home and day to day, the present structures within medicine where doctors can come together to train, work, play, and reflect together have been reduced or removed completely, and some have been moved to the sterile virtual world.

The lack of those informal spaces threatens our ability to build the resilience we need to work. I'm not suggesting that we reintroduce learning dissection to help fill the gap. But, if we expect doctors to survive a lifetime in medicine, we must bring back the opportunities for them to be together without the threat of inspection, regulation, or monitoring.

Competing interests: I am a former chair of the Royal College of General Practitioners, a partner of the Hurley Group, and shareholder of eConsult. I am also a non-executive director at University College London Hospitals and a member of the General Medical Council's independent inquiry on gross negligence manslaughter

Provenance and peer review: Commissioned; not externally peer reviewed.

1 Sándor I, Birkás E, Györffy Z. The effects of dissection-room experiences and related coping strategies among Hungarian medical students. BMC Med Educ 2015;15:73. 10.1186/s12909-015-0355-9. 25880170

2 Hafferty FW. Cadaver stories and the emotional socialization of medical students. $J$ Health Soc Behav 1988;29:344-56. 10.2307/2136868. 3253325

Published by the BMJ Publishing Group Limited. For permission to use (where not already granted under a licence) please go to http://group.bmj.com/group/rights-licensing/ permissions 